\title{
LOS OJOS EN EL CÓDIGO DE HAMMURABI
}

\author{
SAMPEDRO A ${ }^{1}$, BARBÓN JJ ${ }^{1}$
}

La civilización mesopotámica se desarrolló entre los ríos Tigris y Eufrates desde el neolítico, y el primer pueblo del que tenemos noticia histórica es el sumerio, los inventores de la escritura cuneiforme. Hammurabi (1792-1752 a de C.) fue el sexto rey de la I dinastía de Babilonia, región que se convirtió durante su reinado en la potencia dominante y unificadora de Mesopotamia. En torno a 1752 a de C., cerca del final de su vida, proclamó un edicto o código en el que se regulaban tarifas y precios y se fijaban unas normas de derecho penal y matrimonial, a través de una colección de 282 sentencias o decretos que nos retratan a la sociedad babilónica de la época. Este Código de Hammurabi, que constituye la primera gran recopilación de leyes escritas de la historia de la humanidad, fue esculpido en una serie de estelas que se repartieron por diferentes ciudades del reino; una de ellas seria llevada como trofeo de guerra a Susa, en el s. XII a de C., donde seria redescubierta en 1902 y trasladada al Museo del Louvre.

Las leyes establecían una proporcionalidad jurídica entre la agresión o daño y el castigo, teniendo en cuenta la intencionalidad y la clase social a la que pertenecía la víctima y el agresor. El Código de Hammurabi diferenciaba tres clases de individuos: los súbditos o siervos, normalmente sometidos a cargas agrícolas (muskenun), la élite de hombres libres (awilum), y por ultimo los esclavos (wardum) que podían acceder al status de muskenun comprando su libertad. Las leyes intentaban recortar el poder absoluto del cabeza del clan familiar en la sociedad mesopotámica, establecido a través de las leyes consuetudinarias (de la costumbre), que le permitían incluso ejecutar a cualquier miembro de la familia y vender a su esposa e hijos. En esta estructura patriarcal el padre solía tener una sola esposa, aunque podía tomar una esclava como concubina, los hijos varones se repartían la herencia mientras que las hijas vivían en la casa paterna hasta el matrimonio.

La mayoría de los castigos recogidos en el Código consistían en multas, sobre todo cuando el agresor tenía mayor categoría social que el agredido, eran frecuentes las penas de mutilación y la pena de muerte, a veces incluso para algunos delitos menores. La ley del Talión, el ancestral «ojo por ojo y diente por diente», solía reservarse como compensación legal cuando ofensor y ofendido eran de la clase dominante.

Hay dos teorías sobre la aplicación real de estas leyes del Código de Hammurabi, una que sustenta su ejecución efectiva, y otra que no cree en una apli-

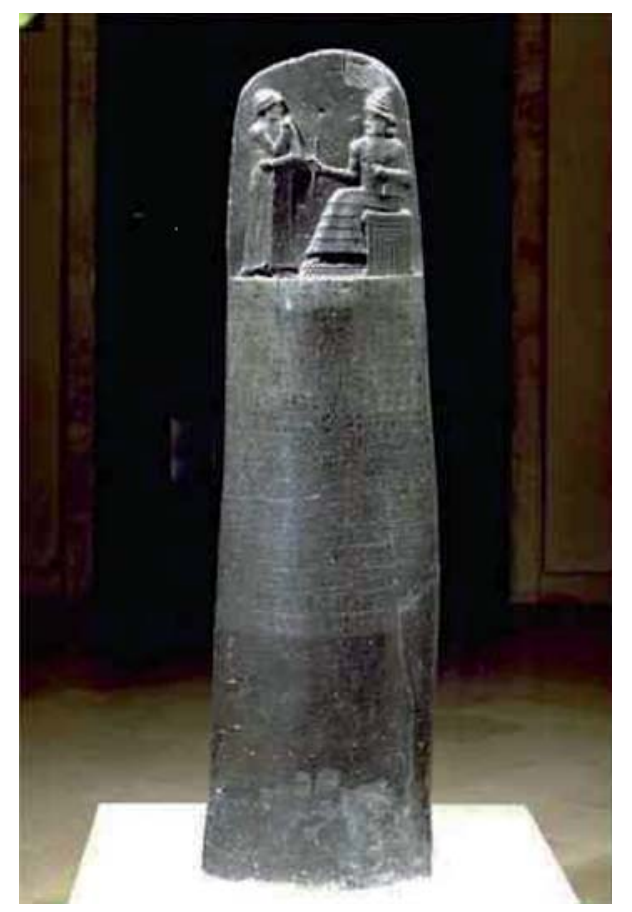

Fig. 1: Estela donde se hallan grabadas las 282 leyes del Código de Hammurabi.

\footnotetext{
${ }^{1}$ Licenciado en Medicina. Servicio de Oftalmología. Hospital San Agustín de Avilés. Asturias. España. 
cación tan estricta y defiende más un valor simbólico de la legislación, presuponiendo que muchas de las penas se evitarían recurriendo a compensaciones económicas.

El castigo de cegamiento y la regulación de una primitiva práctica oftalmológica aparecen recogidos en 9 sentencias:

193. Si el hijo (adoptivo) de un cortesano o el hijo de una hierodula (concubina) termina dando con la casa de su padre y desdeña al padre que lo ha criado o a la madre que lo ha criado y se marcha de la casa de su padre, que le saquen un ojo.

196. Si un hombre (notable) deja tuerto a otro (notable), que lo dejen tuerto a el.

198. Si deja tuerto a un individuo cualquiera (humilde) o le rompe un hueso a un individuo cualquiera (humilde), pagará una mina de plata.

199. Si deja tuerto al esclavo de un hombre o le rompe un hueso al esclavo de un hombre, pagara la mitad de su valor.

215. Si un medico realiza una incisión profunda en un hombre (notable) con bisturí de bronce y le salva la vida al hombre, o si se le abre la nube de un ojo a un hombre (notable) con bisturí de bronce y le salva un ojo al hombre, se quedara con 10 siclos de plata.

216. Si es el hijo de un individuo cualquiera, se quedará con 5 siclos de plata.

217. Si es el esclavo de un hombre, se quedará con 2 siclos de plata.

218. Si un médico realiza una incisión profunda en un hombre (notable) con bisturí de bronce y le provoca la muerte, o si le abre la nube de un ojo a un hombre (notable) con bisturi de bronce y deja tuerto al hombre, que le corten la mano.

220. Si le abre la nube de un ojo con un bisturí de bronce (a un esclavo) y lo deja tuerto, pagará en plata la mitad de su valor.

La interpretación de las sentencias 215 y 216 como alusiones a una primitiva cirugía de cataratas no es del todo clara, ya que el término «nakaptu» puede ser traducido como dacriocistitis o también como nube, referencia más clara a una catarata. Sin embargo, el texto incompleto de otra tablilla coetánea parece probar de forma fehaciente la práctica de la cirugía de la catarata, ya que dice: Si el ojo derecho o izquierdo de un hombre está recubierto de una sombra, con el bisturí... La cirugía se trataría, probablemente, de un abatimiento con un instrumento punzante. A favor de la catarata también apuntaría el hecho de tratarse de una enfermedad $\tan$ frecuente que quedaría muy justificada la regulación legal de su práctica quirúrgica.

En las llamadas Leyes de Esnunna, capital de un reino babilónico (el país de Warum) que sería anexionado por Hammurabi, y por lo tanto ligeramente más antiguas, las lesiones corporales recogidas, como la lesión de un ojo, se castigaba con multas en metálico, sin recurrir al talión: Si un hombre muerde la nariz a otro hombre y se la arranca: pagará 1 mina de plata. Un ojo: una mina, un diente: 1/2 mina; una oreja 1/2 mina. Una bofetada en la cara: pagará 10 siclos de plata.

En las culturas de la antigua Mesopotamia la concepción de la enfermedad era puramente religiosa. Los sanadores sacerdotales realizaban un diagnóstico bien mediante el interrogatorio ritual del paciente buscando una impureza moral como causa, o bien mediante la adivinación, para la que utilizaban la astrología y la hepatoscopia, es decir, la lectura de señales en el hígado de animales sacrificados. El tratamiento consistía en exorcismos, plegarias y sacrificios a los dioses pero sin renunciar a la farmacopea con ingredientes vegetales, minerales y baños.

Existían también unos sanadores de rango inferior, una especie de cirujanos -barberos a los que se refiere el Código con estas leyes tan implacables y duras. La curación de una catarata a un noble sólo les reportaba una ganancia de 10 siclos (unos $80 \mathrm{gr}$ de plata), mientras que el fracaso quirúrgico suponía un traumático fin para la carrera del cirujano que perdía la mano (ambas en otras traducciones). En caso de tratarse de un paciente esclavo la operación exitosa se saldaba con 2 siclos de plata (unos 16 gr.), mientras que el fracaso le obligaba a restituir a modo de indemnización la mitad del precio total del esclavo.

\section{BIBLIOGRAFÍA}

- Sanmartin J. Códigos legales de tradición babilónica. Barcelona: Ed Trotta. 1999.

- López Piñero JM. La medicina en la Historia. Madrid: La esfera de los Libros. 2002.

- Ophtalmologie de Mesopotamie. Disponible en: www.snof.org

- Cotallo JL, Esteban M. La catarata en la historia de la humanidad. In: Lorente R, Mendicute J. Cirugía del cristalino. 84 Ponencia de la Sociedad Española de Oftalmología 2008; vol. 1, cap. 1: 1-29. 